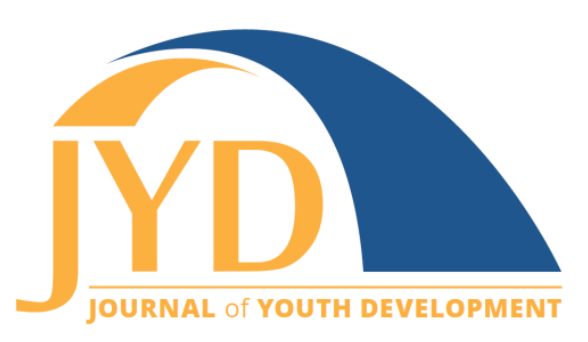

http://jyd. pitt. edu/ | Vol. 13 Issue 4 DOI 10.5195/jyd.2018.572 | ISSN 2325-4017 (online)

\title{
Music Education as a Path to Positive Youth Development: An El Sistema-Inspired Program
}

\author{
Michelle Marie Hospital \\ Florida International University \\ michelle.hospital@fiu.edu \\ Staci Leon Morris \\ Florida International University \\ morris/@fiu.edu
}

Eric F. Wagner

Florida International University

wagnere@fiu.edu

\section{Eva Wales}

Florida International University

ewales@fiu.edu

\begin{abstract}
The El Sistema music education philosophy links positive individual and social development through musical education. This study is a longitudinal examination of the impact of participation in an El Sistemainspired program, the Miami Music Project, on positive youth development. We hypothesized that over the course of a school year, participation in ensemble-based after-school music programming would significantly enhance factors associated with positive youth development. Specifically, we evaluated social emotional constructs aligned with the 5 Cs of Positive Youth Development: Competence, Confidence, Caring, Character, and Connection. Results revealed that participants showed significant increases across all 5 Cs over the course of the year. Additionally, findings showed that Miami Music Project students showed greater enhancements over time in Character, Competence and Caring when compared to a group of youth who did not participate in music education. This study presents empirical documentation of the numerous meaningful social and emotional enhancements that participation in an El Sistemainspired program is engendering among youth. In this type of rigorous orchestral model of musical instruction, youth seem to acquire not only cognitive benefits but also a host of social and emotional enhancements, ostensibly from learning in an environment that requires disciplined social cohesion.
\end{abstract}

(cc) EY New articles in this journal are licensed under a Creative Commons Attribution 4.0 License. This journal is published by the University Library System, University of Pittsburgh and is cosponsored by the University of Pittsburgh Press. The Journal of Youth Development is the official peer-reviewed publication of the National Association of Extension 4-H Agents and the National AfterSchool Association. 
Music Education as Positive Youth Development

These findings provide insight into the holistic approach foundational to the El Sistema philosophy and adds to our overall understanding of musical instruction in important ways.

Key words: music education, positive youth development, social emotional learning, evaluation

Music has a special ability to alter emotional states. Students who study instrumental music have an enhanced ability to focus when they're engaged in other work, and they're more able to deal with stressful situations most common in urban environments (Creedon, 2011, p. 35).

There is growing empirical evidence that youth who receive music education demonstrate lower rates of substance use, greater academic performance, enhanced executive functioning, and improved conduct (e.g., Devroop, 2012; Hallam, 2010; Sachs, Kaplan, Der Sarkissian, \& Habibi, 2017). Music education, particularly when ensemble-based, appears to engage a range of positive youth development (PYD) skills, and (a) leads to self-awareness, (b) fosters selfexpression through creating music, (c) strengthens self-regulation through learning to read and play music, and (d) promotes social awareness and collaboration through ensemble performance (Edgar, 2013; Pellitteri, 2006). Despite the foregoing, empirical investigations of ensemble-based music education impacts on positive youth development constructs are scant (Hospital et al., 2015).

The primary objective of this study was to determine if involvement in an ensemble-based after-school music program leads to enhanced positive youth development. Specifically, we evaluated whether or not program participation impacted the five Cs of positive youth development: competence, confidence, caring, character, and connection (Lerner, 2004; Lerner, Lerner, Urban, \& Zaff, 2016).

\section{The El Sistema Music Education Approach}

The El Sistema music education philosophy, which aims to create positive individual and social development through musical education, was developed by economist and musician, José Antonio Abreu, as a reaction to the severe poverty in Venezuela in the 1970's (Tunstall, 2012). The guiding principle of the El Sistema philosophy is that social change can be achieved through the pursuit of musical excellence, using a rigorous ensemble model of instruction (Abreu, 2009). One of the key distinctions from the more traditional Western-oriented model of music 


\section{Music Education as Positive Youth Development}

education, which emphasizes individual instruction, is El Sistema's focus on learning through frequent, rigorous participation in an ensemble setting. El Sistema was designed with two primary ideas: the arts are for everyone, not only for the talented and wealthy; and the joint successes and performances of the ensemble reinforce healthy individual development, which has positive ripple effects in the community at large (Govias, 2011).

The implementation of the El Sistema approach is burgeoning in the United States (e.g., Youth Orchestra Los Angeles [YOLA], Play on Philly) as well as in other countries (e.g., Scotland's Big Noise). However, despite the proliferation of El Sistema-inspired programs, there is very little empirical data documenting the impact of participation in these programs and a limited understanding of the impact they are having on youth development. The nature of ensemblebased musical instruction involves not only adult-student mentoring but also peer mentoring and high levels of shared responsibility and social cohesion among the orchestra. This may lead to positive social and emotional developmental enhancements not found in traditional individual musical instruction.

For the present study, we partnered with the Miami Music Project (MMP), a Florida-based, nonprofit arts and social development organization founded in 2008 by world-renowned conductor James Judd. The MMP Children and Youth Orchestras program has achieved national prominence as one of the largest El Sistema-inspired programs based in the United States and provides tuition-free, multi-year, after-school, ensemble-based musical education programming. Through a university-community partnership funded by the Ware Foundation, our university partnered with MMP to conduct a comprehensive study evaluating the ways in which participation in an El Sistema-inspired program impacts the positive youth development of its students.

\section{Methods}

\section{Procedures}

Conducting an evaluation of MMP was complex, given that MMP operates in multiple chapters in disparate geographic locations across South Florida that are quite diverse socioeconomically, culturally, racially, and ethnically (for this report MMP chapters shall be identified as Chapters 1 , 2 , and 3). Therefore, we involved key stakeholders familiar with each chapter location in the design of the study. Data collection focused on one chapter each year. 


\section{Music Education as Positive Youth Development}

This study protocol was approved and reviewed annually by the university Institutional Review Board for compliance with human subjects' protections. After obtaining written informed consent, MMP music students and their parents were asked to complete a survey at multiple time points throughout the school year. Recruitment announcements were made by research staff at program rehearsals and parent meetings. Using a quasi-experimental design, we examined the quantitative data collected at the beginning and end of the school year (i.e., pretest-posttest). Survey data were collected from MMP music students ( $n=180$; ages 8 to 17), their parents (i.e., primary caregiver; $n=178$ ), and each participant's lead MMP teaching artist $(n=24)$. Each participant received a $\$ 10$ gift card for completing each assessment.

\section{Miami Music Project - Program Overview and Structure}

MMP incorporates the El Sistema philosophy of using music as an instrument for social transformation, and empowering children to acquire values and to achieve their full potential. The program offers tuition-free, multi-year, music education in multiple under-resourced communities. MMP includes children from first through $12^{\text {th }}$ grades, of all cultural, racial, and socio-economic backgrounds. No musical background is required. Students attend classes after school, 3 to 5 days a week for up to 10 hours per week and their curriculum adheres to the National and Florida State Standards for Music Education. Students receive ensemble-based instruction through full orchestra, large and small sectional rehearsals, choir and other musical ensembles. This is supplemented with private lessons to maximize the potential trajectory of each student.

The MMP program chapters serve Miami's most under-resourced and immigrant communities, predominantly of Haitian-American, African-American, and Hispanic descent. Program chapter locations address the unique needs of their respective communities, yet remain strongly interconnected. Students receive the same curriculum across chapters and many of the teaching artists work at multiple chapters. With regard to performances, students from each chapter frequently conduct concerts at program sites where daily programming occurs, which engages families and members of the surrounding neighborhood. Additionally, students have multiple opportunities throughout the year to perform together (all chapters combined) at large, major performing arts venues across the city. 


\section{Measures}

We assessed participants using a variety of questions in order to capture the five dimensions of PYD as follows:

- Character: The Grit scale developed by Duckworth and Quinn (2009) is an 8-item selfreport scale, which measures trait-level firmness of character, perseverance, and passion for long-term goals by using statements such as, "I finish whatever I begin." Response scores ranged from 1 (not at all like me) to 5 (very much like me).

- Confidence: The short version of Bandura's multidimensional scale of perceived selfefficacy (2006) was used to measure children's sense of confidence. This 18-item questionnaire measured how confident participants felt across a variety of domains on a 4-point Likert scale ranging from 1 (not at all confident) to 4 (very confident).

- Caring: The 4-item scale of empathy developed by the Positive Indicator Project (www.childtrends.org) was used to assess teen respondents' abilities to feel and understand what someone else is feeling (e.g., "I feel bad when someone gets their feelings hurt"). Response scores ranged from 1 (not at all like me) to 4 (exactly like me).

- Competence: The Children's Hope Scale (CHS), developed by Snyder et al. (1997), was used to measure youth competence. This 6-item scale asked respondents to report on their feelings of optimism, competence, and goal-directed thinking, such as "When I have a problem, I can come up with lots of ways to solve it." Response scores ranged from 1 (none of the time) to 4 (most of the time).

- Connection: Students were asked to report their feelings of connection with the overall program and with their teaching artists, such as "I feel accepted at Miami Music Project, "and "I feel as though my MMP Teaching Artist really cares about me." Response scores ranged from 1 (none of the time) to 4 (most of the time).

We also collected data from parents including demographics, stress, discrimination, academic grades, history of musical involvement, music class attendance, frequency of home practice, progression with learning music, and participation in concerts.

\section{Sample}

\section{Miami Music Project Students}

Music student participants $(N=180)$ were highly representative of the overall MMP student population-ages ranged from 8 to 17 years old ( $M=10$ years, $S D=1.6$ years). Most ( $84 \%)$ were either in their first or second year of participation in the MMP program. Girls made up 
$57 \%$ of the sample. Almost a quarter of the sample reported having been born outside the United States. A majority (54\%) of students identified their race as either Black/AfricanAmerican or multi-racial. Almost half (48\%) identified themselves as Hispanic/Latino, but this varied significantly by chapter (Table 1 ).

Table 1. Race, Ethnicity Distribution by MMP Chapter

\begin{tabular}{|l|c|c|c|c|}
\hline Ethnicity & Total sample & Chapter 1 & Chapter 2 & Chapter 3 \\
\hline Hispanic & $48 \%$ & $83 \%$ & $44 \%$ & $10 \%$ \\
\hline Race & & & & \\
\hline White & $31 \%$ & $49 \%$ & $38 \%$ & $4 \%$ \\
\hline Black/African-American & $47 \%$ & $17 \%$ & $49 \%$ & $77 \%$ \\
\hline Multi-racial & $7 \%$ & $9 \%$ & $7 \%$ & $7 \%$ \\
\hline Other & $17 \%$ & $24 \%$ & $6 \%$ & $10 \%$ \\
\hline
\end{tabular}

Note. Chapter 1 was significantly more likely $(p<.05)$ to report their ethnicity as Hispanic/Latino and Chapters 2 and 3 were significantly more likely $(p<.05)$ to report their race as Black.

\section{Descriptive Information}

We conducted quantitative analyses using the IBM SPSS statistical software program (version 20). Below, we present descriptive frequencies for a variety of responses and we conducted one-way analysis of variance (ANOVA) tests to examine whether or not these frequencies varied significantly $(p<.05)$ by chapter.

Prior musical involvement. Most (85\%) student participants were in their first or second year in MMP. Almost half (48\%) of participants reported having had some form of musical training before enrolling in MMP; this varied by chapter. Post hoc comparisons by chapter revealed a significantly $(p<.05)$ higher average likelihood that Chapter 1 students had some previous experience with music, ranging from private lessons to in-school music classes, as compared to students from the other two chapters.

Music class attendance. Comparisons by chapter on class attendance revealed a significantly ( $p$ $<.05)$ lower average attendance at Chapter 3 as compared to the other two chapters. The most commonly reported reason for missing classes was students having too much homework. Other reasons listed included: illness, family problems, other activities/sports, travel, and medical appointments. 
Participation in MMP concerts. Most (88\%) students participated in at least one concert throughout the previous year and $95 \%$ reported enjoying participating in the concert(s). These findings did not vary significantly by chapter. Students were asked to write what they liked most about participating in the concerts. Notable frequent responses were, "everything," "playing together," "playing for parents," "feel loved," and "happy."

\section{Parents of Miami Music Project Students}

Most parent participants were mothers (80\%) and the majority (54\%) were not born in the United States. As expected, parent language preference varied by chapter as follows:

- Chapter 1: 44\% preferred Spanish.

- Chapter 2 39\% preferred Haitian Creole (Kreyòl) and 27\% preferred Spanish.

- Chapter 3: 98\% preferred English.

Almost half (47\%) reported having experienced some form of discrimination in their lifetime. This result did not differ significantly by chapter. However, when asked if discrimination had interfered with having a full and productive life, there were significant differences by chapter $[f(2,177)=12.49, p<.001)]$. Chapter 3 parents were more likely to report that discrimination had a large impact on their lives as compared to parents from the other two chapters.

Parents' reports of most common life stressors varied by chapter as follows: parents from Chapter 3 reported greater percentages of all life stressors than the other two chapters. They also identified "Death of a close family friend/relative" and "Serious illness of a family member" as the most frequent life stressors. By contrast, Chapter 1 reported "Moved to a new house" and "New baby" as the most frequent life stressors. Differences in race/ethnicity, discrimination and life stressors by chapter highlight the sizeable diversity across the program.

\section{Non-Music Comparison Group}

We also collected data at the Chapter 3 location from a comparison group of children $(n=60)$ who were participating in other after-school programs but were not music students. Comparison group participant ages ranged from 8 to 17 years old ( $M=11.6$ years old, $S D=3$ years). Girls made up $58 \%$ of the comparison group sample and $4 \%$ reported having been born outside the United States. Most (90\%) of the comparison group participants reported their race as either Black/African-American or multi-racial and $9 \%$ identified themselves as Hispanic/Latino. Over three fourths $(82 \%)$ of the comparison group reported having participated in at least one type 


\section{Music Education as Positive Youth Development}

of after-school activity during the school year. The most commonly reported after-school activities were sports, Big Brothers/Big Sisters club, art programs, and dance lessons.

\section{Data Analytic Strategy}

To examine the impact of MMP participation over time, we conducted one-way repeatedmeasures ANOVA tests to evaluate changes over the course of one school year by comparing within group differences with time (Time $1=$ Baseline and Time $2=$ End-of-year) as the repeated measures factor. Additionally, to assess for a possible dosage effect, we also examined whether or not change over time varied by MMP music class attendance and amount of time spent practicing instrument at home. We used general linear model mixed ANOVA's to evaluate whether or not changes over time varied significantly by chapter. Significant $(p<.05)$ findings are presented in the results section.

To evaluate whether changes across time varied between the MMP music student participants group (Music group) and the comparison group (Non-Music group), we used the mixed ANOVA analytic technique, with Group (Music vs. Non-Music groups) as the between subjects factor and Time (Time $1=$ Baseline and Time $2=$ End-of-year) as the repeated measures factor. An evaluation of demographic differences between the Music group and the Non-Music group participants revealed that the two groups differed significantly $(p<.05)$ in age and race. On average, the Non-Music group participants were slightly older and more likely to identify their race as Black/African-American. A commonly used technique for accommodating these types of group differences is to include age and race as covariates in the analytic modeling. However, since group membership was non-randomly assigned, including them as covariates would introduce bias into the estimate of the group effect (Miller \& Chapman, 2001). This is particularly true for small sample sizes. Therefore, in lieu of using covariates, supplemental single degree of freedom regression interaction analyses (Jaccard, 1998) were conducted to examine whether age or race were significantly related to the change over time by group. Findings from these supplemental interaction analyses are reported below when significant.

\section{Results}

\section{Changes in the Five Cs of Positive Youth Development}

MMP student participants reported enhancements across all five Cs of positive youth development over the course of a school year. 


\section{Character}

Findings revealed that on average MMP students showed significant increases in character over the course of the school year. We found a statistically significant increase in average MMP students' grit over time from Baseline to the End-of-year $\left[M_{\text {Baseline }}=3.47(.71), M_{\text {End-of-year }}=\right.$ $\left.\left.3.62(.76) ; f(1,146)=4.89, \mathrm{p}<.05, \eta^{2}=.03\right)\right]$. Interaction analyses by chapter revealed no statistically significant differences. In other words, all chapters showed a similar significant increase.

\section{Competence}

Findings revealed that on average MMP students showed significant increases in competence as measured by academic grades, hope, and musical competence over the course of the school year.

Grades. Parent participants were asked, "Have you noticed any changes in your child's grades over the past year?" Overall, a majority (51\%) reported improvement, of which $53 \%$ attributed this improvement to participation in MMP. Comparisons by chapter revealed significant $(p<$ .05) average differences across chapter as noted in Table 2.

Table 2. Percentage of Parents Reporting Academic Improvements by Chapter

\begin{tabular}{|l|c|c|c|c|}
\hline & Total & Chapter 1 & Chapter 2 & Chapter 3 \\
\hline $\begin{array}{l}\text { Percentage of parents who reported } \\
\text { child's academic grades improved }\end{array}$ & $51 \%$ & $32 \% *$ & $68 \%$ & $57 \%$ \\
\hline $\begin{array}{l}\text { Percentage of parents who attributed } \\
\text { improvement to participation in MMP }\end{array}$ & $53 \%$ & $44 \%$ & $63 \%$ & $53 \%$ \\
\hline
\end{tabular}

*Percentage for chapter 1 was significantly $(p<.05)$ lower than chapters 2 and 3.

Goal-directed hope. The average MMP students' sense of overall hope (optimism, feelings of competence and goal-directed future) increased significantly from Baseline to the End-of-year $\left[M_{\text {Baseline }}=3.42(.55), M_{\text {End-of-year }}=3.52(.59) ; f(1,143)=5.44, p<.05, \eta^{2}=.04\right]$.

Supplemental interaction analyses revealed that this finding was significantly stronger the more the students reported having practiced their instrument at home. 
Musical progression. MMP student participants were asked to rate their own musical progression at the end of the year. Most students (92\%) reported improvement in their ability to read music ("A lot" $=60 \%$, "Some" $=32 \%$ ) with only a small percentage reporting minimal improvement ("Very little" $=5 \%$, "None" $=3 \%)$. With regard to playing music, almost all $(92 \%)$ reported improvement ("A lot" $=71 \%$, "Some" $=21 \%$ ). There were no significant differences by chapter for either question.

\section{Caring/Compassion}

Findings revealed that on average MMP students showed significant increases in caring/compassion as measured by empathy over the course of the school year. There was a significant increase in average MMP student teen participants' sense of empathy over time from Baseline to the End-of-year $\left[M_{\text {Baseline }}=3.23(.65), M_{\text {End-of-year }}=3.59(.45) ; f(1,31)=8.05, p<\right.$ $\left..05, \eta^{2}=.21\right)$ ]. Interaction analyses by chapter revealed no significant differences. In other words, all chapters showed a similar significant increase.

\section{Confidence}

Findings revealed that on average MMP students showed significant increases in overall selfconfidence as measured by self-efficacy over the course of the academic year. There was a significant increase in average MMP student participants' sense of self-efficacy over time from Baseline to the End-of-year [ $M_{\text {Baseline }}=3.30(.47), M_{\text {End-of-year }}=3.42(.48) ; f(1,114)=6.02, p<$ $\left..05, \eta^{2}=.05\right]$. Interaction analyses by chapter revealed no significant differences. In other words, all chapters showed a similar significant increase.

\section{Connection}

Findings revealed that at the end of the school year, most MMP students reported a strong sense of connection with the MMP program as well as with their MMP teaching artists.

Connection with MMP program. Frequency distributions of the end-of-year assessment revealed that after at least one year of participation, most students felt a strong sense of connection to MMP. These findings did not vary significantly by chapter. Response rates (from students on all three chapters) to questions about their connection to the MMP program are shown in Table 3. 
Journal of Youth Development | http://jyd.pitt.edu/ | Vol. 13 Issue 4 DOI 10.5195/jyd.2018.572

Music Education as Positive Youth Development

Table 3. Student Responses to Questions Regarding Connection to the MMP Program.

\begin{tabular}{|l|c|c|c|}
\hline Connection to the MMP program & $\begin{array}{c}\text { A lot or most of } \\
\text { the time }\end{array}$ & Sometimes & Never \\
\hline Do you feel comfortable at MMP? & $81 \%$ & $12 \%$ & $7 \%$ \\
\hline Do you feel supported by MMP? & $87 \%$ & $5 \%$ & $8 \%$ \\
\hline Do you feel accepted at MMP? & $86 \%$ & $10 \%$ & $4 \%$ \\
\hline
\end{tabular}

Connection with MMP teacher. We found similar results when examining whether or not MMP students felt a sense of connection with their MMP teaching artists, as shown in Table 4.

Table 4. Student Responses to Questions Regarding Connection to the MMP Teaching Artists.

\begin{tabular}{|l|c|c|c|}
\hline $\begin{array}{l}\text { Connection to the MMP teaching } \\
\text { artist }\end{array}$ & $\begin{array}{c}\text { Most or half of } \\
\text { the time }\end{array}$ & $\begin{array}{c}\text { Some of the } \\
\text { time }\end{array}$ & $\begin{array}{r}\text { None of the } \\
\text { time }\end{array}$ \\
\hline $\begin{array}{l}\text { Do you feel special when you're with } \\
\text { your MMP teaching artist? }\end{array}$ & $77 \%$ & $13 \%$ & $10 \%$ \\
\hline $\begin{array}{l}\text { Did you learn a lot from your MMP } \\
\text { teaching artist? }\end{array}$ & $87 \%$ & $12 \%$ & $2 \%$ \\
\hline $\begin{array}{l}\text { Do you feel your MMP Teaching } \\
\text { artist really cares about you? }\end{array}$ & $83 \%$ & $10 \%$ & $7 \%$ \\
\hline
\end{tabular}

\section{Differences Between Music and Non-Music Groups over Time}

\section{Character}

Findings revealed a significant Time (Baseline vs. End-of-year) by Group (Music vs. Non-Music) interaction effect $\left[F(1,196)=10.89, M S E=3.45, p<.05, \eta^{2}=.01\right]$. This indicated that on average the Music group reported significantly greater increases in grit than Non-Music group over the course of the school year (Table 5). Supplemental regression interaction analyses showed that this difference did not vary by age or by race. 
Music Education as Positive Youth Development

Table 5. Baseline and End-of-Year Mean Scores by Group

\begin{tabular}{|c|c|c|c|c|}
\hline \multirow[b]{2}{*}{$\begin{array}{l}\text { Construct }^{+} \\
\text {(Variable Name) }\end{array}$} & \multicolumn{2}{|c|}{ MMP group } & \multicolumn{2}{|c|}{ Non-MMP group } \\
\hline & $\begin{array}{c}\text { Baseline* } \\
M(S D)\end{array}$ & $\begin{array}{c}\text { End-of-Year } \\
\qquad M(S D)\end{array}$ & $\begin{array}{c}\text { Baseline* } \\
M(S D)\end{array}$ & $\begin{array}{c}\text { End-of-Year } \\
\qquad M(S D)\end{array}$ \\
\hline $\begin{array}{l}\text { Character } \\
\text { (Grit) }\end{array}$ & $3.47(.71)$ & $3.62(.76)$ & $3.68(.74)$ & $3.39(.64)$ \\
\hline $\begin{array}{l}\text { Competence } \\
\text { (Goal-directed hope) }\end{array}$ & $3.41(.53)$ & $3.52(.59)$ & $3.38(.54)$ & $3.35(.59)$ \\
\hline $\begin{array}{l}\text { Caring } \\
(\text { Empathy)** }\end{array}$ & $3.23(.65)$ & $3.59(.45)$ & $3.09(.78)$ & $2.96(.71)$ \\
\hline $\begin{array}{l}\text { Confidence } \\
\text { (Self-efficacy)** }\end{array}$ & $3.87(.66)$ & $3.96(.82)$ & $3.88(.67)$ & $3.50(.56)$ \\
\hline
\end{tabular}

Notes. *Baseline differences across groups (Music vs. Non-Music) were non significant. ** The reported caring and confidence scales were completed only by participants aged 12 and older. ${ }^{+}$Connection was measured only among MMP students, so no comparison analyses could be conducted for this construct.

\section{Competence}

Findings revealed a significant Time (Baseline vs. End-of-year) by Group (Music vs. Non-Music) interaction effect $\left[\left(f(1,194)=4.38, M S E=.75, p<.05, \eta^{2}=.02\right)\right]$. On average, the mean score of goal-directed hope increased for MMP students but essentially stayed the same for Non-MMP youth participants (Table 5). Supplemental regression interaction analyses showed that this difference did not vary by age. However, there was a significant interaction by race. In other words, the effect by group on average varied by the race of the participant but we were not able to further explain this difference due to sample size limitations, and because race was confounded by chapter.

\section{Caring/Compassion}

Findings revealed a significant Time (Baseline vs. End-of-year) by Group (Music vs Non-Music) interaction effect $\left[\left(F(1,50)=4.98, M S E=1.40, p<.05, \eta^{2}=.09\right)\right]$. On average, the mean score of empathy increased for the Music group but decreased for Non-Music group (Table 5). Supplemental regression interaction analyses showed that this difference did not vary by age or race. 


\section{Confidence}

Findings revealed a significant Time (Baseline vs. End-of-year) by Group (Music vs. Non-Music) interaction effect $\left[\left(f(1,50)=8.13, M S E=1.31, p<.05, \eta^{2}=.14\right)\right]$. This indicated that on average the Music group reported significantly greater increases in confidence than Non-Music group over the course of the school year (Table 5). However, supplemental analyses revealed that there was a significant interaction by age. In other words, the effect by group on average varied by the age of the participant but we were not able to further explain this difference due to sample size limitations, and because age was confounded by group.

\section{Discussion}

This study empirically documented numerous meaningful social and emotional gains among youth who participated in an El Sistema-inspired program. Significant enhancements were found across all three program chapters, despite their differences with regard to geographic location, race, ethnicity, culture, and language. Moreover, data were collected across three different years, precluding history effects.

The current study suggests that positive impacts of participation in ensemble-based musical instruction exceed the cognitive benefits of individual musical training (e.g., Collins, 2014; Hyde et al., 2009). Brain research has stipulated that programs that actively include social components promote neuroplasticity and enhance learning (Beaulieu \& Sharpe, 2015). The El Sistema approach seemingly facilitates this by using a holistic ecological perspective; the child is seen as a whole person dynamically interacting within the context in which he/she is embedded (Bronfenbrenner \& Morris, 2006). The rigorous orchestral and community-focused model of El Sistema may provide a unique platform for positive youth development, ostensibly from learning in an environment that not only requires the sensory-motor interactions needed for musical performance, but also disciplined social cohesion, shared responsibility and cooperation embedded within an organizational culture that is student- and community-centered. By documenting the impact of participation in MMP across a broad array of factors associated with positive youth development, we offer support for this holistic approach foundational to the El Sistema philosophy and advance our understanding of musical instruction in important ways.

\section{Limitations}

Even though rigorous, our study had methodological limitations. First, we relied on self- and parent-reports for measuring our target variables. While we have no reason to believe 
participants were providing socially desirable answers, there might have been some bias. Second, our Non-Music comparison group was not as representative as it might have been with regard to age and race, creating a few complications with the statistical analyses. Even though we did account for preexisting demographic differences by group at Baseline, the Non-Music group was not randomly assigned. Future research would be enhanced by conducting a randomized controlled trial where students who express interest in participating in an El Sistema-inspired music program are randomly assigned and then assessed longitudinally. Additionally, future research should attempt to examine the impact of participation in these types of programs on the areas of the brain involved in the development of social emotional learning leading to positive youth development. Studies involving functional magnetic resonance imaging (fMRI) may be particularly interesting in this regard.

\section{Implications}

The findings from this study have important program implications. Specifically, they shed light on the importance of evaluating the impact of program participation on constructs related to positive youth development. As the body of research supporting the centrality of the five Cs of positive youth development continues to grow, future evaluations of youth programs would benefit greatly from direct evaluation of their programs' impacts on five $\mathrm{C}$ indicators. Many after-school youth programs provide a natural and safe space for children to learn and practice social emotional skills associated with positive youth development and lifelong well-being. Further development of knowledge in this area is vital for honing extra- and intra-curricular approaches for promoting positive youth development.

\section{References}

Abreu, J. A. (2009). On kids transformed by music [Video]. Available from TED website: https://www.ted.com/talks/jose_abreu_on_kids_transformed_by_music?language=en

Beaulieu, S., \& Sharpe, K. (2015). Using brain science to boost social and emotional skills. [Brief]. Saint Paul: University of Minnesota Extension Center for Youth Development. Retrieved from https://conservancy.umn.edu/handle/11299/195135

Bronfenbrenner, U., \& Morris, P. A. (2006). The bioecological model of human development. In R. Lerner (Ed.), Handbook of child psychology, (pp. 793-828). Hoboken, NJ: Wiley.

Creedon, D. W. (2011). Fight the stress of urban education with the arts. Phi Delta Kappan, 92(6), 34-36.

Collins, A. (2014). Music education and the brain: What does it take to make a change? Update: Applications of Research in Music Education, 32(2), 4-10. 
Music Education as Positive Youth Development

Devroop, K. (2012). The social-emotional impact of instrumental music performance on disadvantaged South African students. Music Education Research, 14(4), 407-416.

Duckworth, A. L., \& Quinn, P. D. (2009). Development and validation of the short grit scale (GRIT-S). Journal of Personality Assessment, 91(2), 166-174.

Edgar, S. N. (2013). Introducing social emotional learning to music education professional development. Update: Applications of Research in Music Education, 31(2), 28-36.

Govias, J. A. (2011). The five fundamentals of El Sistema. Canadian Music Educator, 53(1), 21-23.

Hallam, S. (2010). The power of music: Its impact on the intellectual, social and personal development of children and young people. International Journal of Music Education, 28(3), 269-289.

Hospital, M., Wagner, E., Morris, S., Pietraszko, A., Brizuela, A. \& Judd, J. (2015). Project TREBLE: An examination of an innovative music education program for promoting resilience among urban minority youth. Poster presented at the $45^{\text {th }}$ annual Urban Affairs Association Conference, Miami, FL.

Hyde, K. L., Lerch, J., Norton, A., Forgeard, M., Winner, E., Evans, A. C., \& Schlaug, G. (2009). Musical training shapes structural brain development. Journal of Neuroscience, 29(10), 3019-3025.

Jaccard, J. (1998). Interaction effects in factorial analysis of variance. Sage University Papers Series on Quantitative Applications in the Social Sciences (Series No. 07-118). Thousand Oaks, CA: Sage.

Lerner, R. M. (2004). Liberty: Thriving and civic engagement among America's youth. Thousand Oaks, CA: Sage.

Lerner, R. M., Lerner, J. V., Urban, J. B., \& Zaff, J. (2016). Evaluating programs aimed at promoting positive youth development: A relational development systems-based view. Applied Developmental Science, 20(3), 175-187.

Miller, G. A., \& Chapman, J. P. (2001). Misunderstanding analysis of covariance. Journal of Abnormal Psychology, 110(1), 40-48.

Pellitteri, J. S. (2006). The use of music in facilitating emotional learning. In J. S. Pellitteri, R. Stern, C. Shelton, \& B. Muller-Ackerman (Eds.), Emotionally intelligent school counseling (pp. 185-199). Mahwah, NJ: Erlbaum.

Sachs, M., Kaplan, J., Der Sarkissian, A., \& Habibi, A. (2017). Increased engagement of the cognitive control network associated with music training in children during an fMRI Stroop task. PloS one, 12(10), e0187254.

Snyder, C. R., Hoza, B., Pelham, W. E., Rapoff, M., Ware, L., Danovsky, M., . . \& Stahl, K. J. (1997). The development and validation of the Children's Hope Scale. Journal of Pediatric Psychology, 22(3), 399-421.

Tunstall, T. (2012). Changing lives: Gustavo Dudamel, El Sistema, and the transformative power of music. New York, NY: WW Norton \& Company. 